\title{
Algumas Notas sobre os Métodos Filosóficos de Ludwig Wittgenstein
}

\author{
[Some Notes on Ludwig Wittgenstein's Philosophical Methods]
}

\section{Gustavo Augusto Fonseca Silva}

\begin{abstract}
Resumo: No artigo "Wittgenstein: universalismo, lógica, gramática y lenguaje", Alejandro Tomasini Bassols afirma que o problema com que Wittgenstein se depara ao fim do Tractatus - as proposições do livro serem elucidações e contrassensos - teve origem em seu erro de considerar a lógica, e não a linguagem, como o mais universal. Bassols afirma ainda que o assim chamado "paradoxo do Tractatus" não foi uma ameaça à segunda filosofia wittgensteiniana porque nela Wittgenstein não cometeu o mesmo erro. Neste artigo argumenta-se que as proposições do Tractatus são contrassensos como consequência direta da teoria pictórica do significado, independentemente da ontologia tractatiana. Além disso, divergindo da opinião de Bassols de ter havido "genuíno progresso filosófico" entre a primeira e a segunda filosofia de Wittgenstein, ressalta-se como o mais sério problema que marca a primeira filosofia wittgensteiniana também marca a segunda: o contrassenso de que Wittgenstein nunca seguiu os próprios métodos filosóficos.
\end{abstract}

Palavras-chave: Ludwig Wittgenstein. Métodos filosóficos. Paradoxo do Tractatus.

\begin{abstract}
In his article "Wittgenstein: universalismo, lógica, gramática y lengaje," Alejandro Tomasini Bassols argues that the trouble Wittgenstein faces at the end of Tractatus - that the propositions contained in his work are elucidations and nonsensical-started with his mistake in considering logic and not language the most universal. Bassols further asserts that the so called "paradox of the Tractatus" was not a threat against the second Wittgensteinian philosophy, because Wittgenstein himself did not make the same mistake. This article argues that the propositions in Tractatus are paradoxical as a consequence of the picture theory of meaning, and regardless of the ontology in Tractatus. In addition, against Bassols's opinion concerning the existence of a genuine philosophical progress between Wittgenstein's first and second philosophies, this article highlights how the main issue in Wittgenstein's first philosophy is also the main issue in his second philosophy: the paradox of Wittgenstein never having followed his own methods.
\end{abstract}

Keywords: Ludwig Wittgenstein. Philosophical methods. Tractatus' paradox.

\footnotetext{
${ }^{\star}$ Doutor em Linguística Teórica e Descritiva pela Universidade Federal de Minas Gerais (UFMG). Atualmente realiza pesquisa de pós-doutorado em linguística na UFMG. E-mail: fonsecaugusto@hotmail.com. ORCID: https://orcid.org/ 0000-0001-7427-4504.
} 
Existem filósofos que (...) tratam a linguagem ordinária como sacrossanta. Eles exaltam a linguagem ordinária até a exclusão de uma de suas próprias características: sua disposição de se manter evoluindo. O próprio neologismo científico é somente evolução linguística que se tornou autoconsciente, assim como a própria ciência é senso comum autoconsciente. E a filosofia, por sua vez, enquanto um esforço de esclarecimento das coisas, não deve ser diferenciada, em pontos essenciais de objetivo e método, da boa e má ciência (QUINE, 2010, p. 24).

\section{Introdução}

No artigo "Wittgenstein: universalismo, lógica, gramática y lenguaje", Alejandro Tomasini Bassols afirma que o problema com que Wittgenstein se depara ao fim do Tractatus logicophilosophicus - o fato de que as proposições do livro são elucidações e contrassensos - surge de seu erro de ter considerado não a linguagem, mas a lógica, como o mais universal (a lógica do mundo e a lógica da linguagem). Com base nessa interpretação, Bassols argumenta que o "paradoxo do Tractatus" (p. 617) - o disparate de que no livro mesmo Wittgenstein "estaria enunciando precisamente o que de acordo com sua própria filosofia é logicamente impossível expressar em palavras" (ibid.) - não representou ameaça alguma à segunda filosofia wittgensteiniana porque, ao desenvolver suas novas ideias, Wittgenstein não incorreu no mesmo erro, sendo esse um "genuíno progresso filosófico” (p. 638). Em oposição à tese de Bassols de que o "paradoxo do Tractatus" é resultado do erro de Witt- genstein de considerar a lógica, e não a linguagem, como o mais universal, neste artigo defende-se a tese de que as proposições contrassensuais do Tractatus são uma consequência direta da teoria pictórica do significado, independentemente da obscura e não fundamentada ontologia tractatiana (cf., p. ex., ANSCOMBE, 1996, p. 29 e p. 97; FOGELIN, 1995, p. 123; SLUGA, 2011, p. 23; STRAWSON, 2002, p. 57). Além disso, em detrimento da avaliação de Bassols de ter havido progresso entre a primeira e a segunda filosofia de Wittgenstein, explicita-se neste artigo como o mais grave problema que marca a primeira filosofia wittgensteiniana também marca a segunda: o contrassenso de que Wittgenstein nunca seguiu os próprios métodos filosóficos isto é, o contrassenso de que Wittgenstein nunca foi wittgensteiniano.

A fim de facilitar a exposição, este texto foi dividido em sete seções. $\mathrm{Na}$ primeira seção demonstra-se como o "paradoxo do Tractatus" é consequência direta da teoria pictórica do significado, a despeito da ontologia tracta- 
tiana. Nessa seção também se analisa a disparidade, observada por exemplo por Peter Hacker (1986, p. 12), entre a teoria da filosofia apresentada no Tractatus e a prática filosófica expressa no livro. Na segunda seção, detalha-se como Wittgenstein jamais seguiu o método filosófico do Tractatus nem antes, nem durante, nem depois de escrevê-lo. Já na terceira seção discute-se o choque entre o místico Wittgenstein e os positivistas lógicos do Círculo de Viena, bem como o contrassensual princípio verificacionista. Na quarta seção, por sua vez, examina-se a discrepância, assinalada por exemplo por Anthony Kenny (2006 p. xix), entre a explicação da filosofia feita por Wittgenstein nas Investigações filosóficas e a atividade filosófica do livro. Adiante, na quinta seção, com o intuito de confirmar e aprofundar a observação de Kenny, assinala-se a incoerência de Wittgenstein de sentenciar nas Investigações que todas as elucidações deveriam desaparecer e ser substituídas por descrições, mas não ter substituído as elucidações do próprio livro por descrições. Na sexta seção, dando continuidade à exposição de como a atividade filosófica nas Investigações filosóficas contrasta com a explicação da filosofia feita por seu autor, aponta-se que Wittgenstein tocou abundantemente no uso efetivo da linguagem, apesar de ter exortado que a filosofia não deveria fazê-lo. Na sétima seção, por fim, sinte- tizando toda a argumentação, enunciase o que se poderia chamar de "paradoxo das Investigações filosóficas": o fato de que o livro, como o Tractatus, não poderia ser sequer escrito utilizando-se o método filosófico nele apresentado.

\section{O contrassensual "método correto da filosofia"}

Como ressaltado por Elizabeth Anscombe em sua clássica introdução ao Tractatus logico-philosophicus, o tema principal do livro "é a ligação entre linguagem, ou pensamento, e a realidade", sendo a tese central sobre isso que "sentenças, ou suas contrapartes mentais, são figuras de fatos (pictures of facts)" 1 (1996, p. 19). Dessa forma, a pedra angular do Tractatus é a sua teoria pictórica do significado:

$\mathrm{Na}$ proposição, o pensamento pode ser expresso de modo que aos objetos do pensamento correspondam elementos do sinal proposicional (3.2).

Chamo esses elementos de "sinais simples"; a proposição, de "completamente analisada" (3.201).

Os sinais simples empregados

\footnotetext{
${ }^{1}$ As traduções das citações de obras não publicadas em português foram feitas pelo autor.
} 
na proposição chamam-se nomes (3.202).

O nome significa o objeto. $\mathrm{O}$ objeto é seu significado (...) (3.203).

À configuração dos sinais simples no sinal proposicional corresponde a configuração dos objetos na situação (3.21).

O nome substitui, na proposição, o objeto (3.22).

A proposição elementar consiste em nomes. É uma vinculação, um encadeamento de nomes (4.22).

A história de como Wittgenstein desenvolveu, durante a Primeira Guerra Mundial, a ideia de que sentenças são figuras de fatos - isto é, são uma figuração da realidade que descrevem - foi anos mais tarde relatada por ele a G. H. von Wright (1990, p. 18-19). De acordo com seu amigo, enquanto prestava serviço no exército austro-húngaro, Wittgenstein leu numa revista uma reportagem sobre um processo em Paris relativo a um acidente de carro. No tribunal, foi apresentado um modelo do acidente, o que levou Wittgenstein à ideia de que o modelo podia figurar o acidente, dada a correspondência entre as partes - ou seja, casas, carros e pessoas em miniatura e as coisas reais: casas, carros e pessoas. Tendo feito uma analogia entre o modelo do acidente e a linguagem, Wittgenstein concluiu que uma sentença, uma proposição, também é um modelo, uma figuração da realidade que descreve: "Na proposição constitui-se experimentalmente um mundo. [Como quando na sala de audiências em Paris se representa com bonecos um acidente automobilístico, etc.]", escreveu Wittgenstein em 29 de setembro de 1914 (WITTGENSTEIN, 2004a, p. 16). "Nessa analogia", comenta Ray Monk (1995, p. 117), "poder-se-ia dizer que uma proposição serve de modelo, ou figuração [ou imagem], de um estado de coisas, em virtude de uma correspondência similar entre as suas partes e o mundo." No entanto, como ponderou Anscombe (1996, p. 79-80), infinitas proposições não servem de modelo, ou figuração [ou imagem], de um estado de coisas, em virtude de uma correspondência similar entre as suas partes e o mundo, como as proposições matemáticas, as proposições que exprimem leis da natureza, as proposições sobre Deus e o significado da vida, as proposições sobre o espaço e o tempo. Fora as proposições filosóficas - incluindo, claro, as do próprio Tractatus. Porém, Wittgenstein não apenas deixou de lado esses contraexemplos à teoria pictórica do significado a fim de preservá-la como traçou com base nela um limite para a expressão dos pensamentos, conforme afirmou no prefácio da obra: 
Poder-se-ia talvez apanhar todo o sentido do livro com estas palavras: o que se pode em geral dizer, pode-se dizer claramente; e sobre aquilo de que não se pode falar, deve-se calar.

O livro pretende, pois, traçar um limite para o pensar, ou melhor - não para o pensar, mas para a expressão dos pensamentos: a fim de traçar um limite para o pensar, deveríamos poder pensar os dois lados desse limite (deveríamos, portanto, poder pensar o que não pode ser pensado).

O limite só poderá, pois, ser traçado na linguagem, e o que estiver além do limite será simplesmente um contrassenso.

Tendo em vista esse limite, Wittgenstein propôs no Tractatus aquele que acreditava ser o "método correto da filosofia":

O método correto da filosofia seria propriamente este: nada dizer, senão o que se pode dizer; portanto, proposições da ciência natural - portanto, algo que nada tem a ver com a filosofia; e então, sempre que alguém pretendesse dizer algo de metafísico, mostrar-lhe que não conferiu significado a certos sinais em suas proposições. Esse método seria, para ele, insatisfatório - não teria a sensação de que lhe estivéssemos ensinando filosofia; mas esse seria o único rigorosamente correto (6.53).

Em carta a Bertrand Russell de 1919, porém, contrariando o que havia afirmado no prefácio do Tractatus sobre a pretensão do livro de traçar um limite não para o pensar, mas para a expressão dos pensamentos, Wittgenstein iguala o pensar à expressão dos pensamentos:

O ponto principal (do Tractatus) é a teoria do que pode ser expresso (gesagt) por proposições - isto é, pela linguagem (e, o que vem a ser o mesmo, o que pode ser pensado) e o que não pode ser expresso por proposições mas apenas mostrado (gezeigt); este, a meu ver, é o problema cardinal da filosofia (MONK, 1995, p. 157).

E este, a meu ver, é o problema cardinal do "método correto da filosofia": se o que pode ser expresso por proposições, isto é, pela linguagem (e, o que vem a ser o mesmo para Wittgenstein, o que pode ser pensado), restringe-se à ciência natural, o Tractatus não poderia ser sequer pensado, muito menos ser expresso por proposições. Assim, “o 
próprio Tractatus, com suas proposições numeradas, fracassa redondamente em aderir a este método. Insistir que essas proposições não são na realidade proposições e sim 'pseudoproposições' ou 'elucidações' é uma evasão evidentemente insatisfatória desta dificuldade central" (ibid., p. 271). Ciente de que o próprio Tractatus fracassa redondamente em aderir ao "método correto da filosofia", ou seja, ciente de que "o livro todo é um contrassenso" (ibid., p. 195), como admitiu em carta a C. K. Ogden de 1922, Wittgenstein apresenta logo em seguida à proposição 6.53 uma "evasão evidentemente insatisfatória desta dificuldade central":

Minhas proposições elucidam dessa maneira: quem me entende acaba por reconhecê-las como contrassensos, após ter escalado através delas - por elas - para além delas. (Deve, por assim dizer, jogar fora a escada após ter subido por ela.)

Deve sobrepujar essas proposições, e então verá o mundo corretamente (6.54).

Levando às últimas consequências o "método correto da filosofia", Wittgenstein sentencia: "Sobre aquilo de que não se pode falar, deve-se calar" (7). No entanto, como observou Bertrand Russell em sua introdução ao Tractatus,
Wittgenstein conseguiu no próprio livro "dizer uma porção de coisas sobre o que não pode ser dito" - ou seja, Wittgenstein não se calou nem no próprio Tractatus sobre aquilo de que supostamente não se pode falar: "o Místico" (6.522).

\section{A expressão do inexprimível}

Na verdade, durante a guerra, enquanto concebia o seu método filosófico, Wittgenstein disse uma porção de coisas que alegadamente só poderiam ser "mostradas" (4.1212), como exemplificam estas anotações metafísicas de seu diário:

Que sei eu acerca de Deus e da finalidade da vida?

Sei que este mundo existe.

Que estou nele como o meu olho no seu campo visual.

Que algo nele é problemático, a que chamamos o seu sentido.

Que este sentido não reside nele, mas fora dele.

Que a vida é o mundo.

Que a minha vontade penetra o mundo. 
Que a minha vontade é boa ou má.

Que, portanto, o bem e o mal se conectam, de algum modo, com o sentido do mundo.

Ao sentido da vida, isto é, ao sentido do mundo, podemos chamar Deus.

E a metáfora de Deus como pai está a isso ligada.

Orar é pensar no sentido da vida.

\section{$(\ldots)$}

(WITTGENSTEIN, 2004a, p. 108).

(..)
WITTGENSTEIN, 2004a, p.
108).

E ainda:

Crer num Deus significa compreender a questão do sentido da vida.

Crer num Deus significa perceber que ainda nem tudo está decidido com os fatos do mundo.

Crer em Deus significa perceber que a vida tem um sentido. $(\ldots)$

Seja como for, somos, em todo o caso, e num certo sentido, dependentes e podemos chamar Deus àquilo de que somos dependentes.

Deus, neste sentido, seria simplesmente o destino ou, o que é a mesma coisa: o mundo - independentemente da nossa vontade (ibid., p. 110).

Considerando-se essas proposições de Wittgenstein, bem como as proposições metafísicas do próprio Tractatus, fica nítido que ele nunca, por assim dizer, jogou fora a escada após ter subido por ela. Não obstante isso, em carta a Ludwig von Ficker de novembro de 1919, Wittgenstein afirmou sobre o seu livro:

(...) a obra consiste em duas partes: a que está aqui e tudo aquilo que eu não escrevi. E a parte importante é precisamente a segunda. Pois a ética é delimitada internamente, por assim dizer, em meu livro; e estou convencido de que, estritamente falando, ela só pode ser delimitada dessa maneira. Em resumo, penso que: tudo aquilo sobre o que muitos hoje estão discorrendo a esmo eu de- 
fini em meu livro simplesmente calando-me a respeito (MONK, 1995, p. 170).

Wittgenstein, no entanto, nunca se calou a respeito de questões éticas, sendo na verdade temido pelos amigos (VON WRIGHT, 1990, p. 28) não apenas por sua "austeridade e intensidade moral inteiramente desconhecidas" (JANIK \& TOULMIN, 1991, p. 9), mas principalmente por ser "implacável" ao julgar os outros (BOUWSMA, 2005, p. 74). Wittgenstein nunca se calou também a respeito de questões estéticas, como revelado por Julian Bell neste poema sarcástico dos anos 1930:

Pois (Wittgenstein) enuncia disparates, muitas afirmações faz,/ Sempre o seu voto de silêncio a quebrar;/ De ética, estética, fala dia e noite,/ E designa as coisas de boas ou más, ou certas e erradas./ (...) Quem, sobre qualquer assunto, já viu/ Ludwig refrear-se de estabelecer a lei?/ Em qualquer companhia ele grita e manda calar,/ Interrompe nossas frases e balbucia as suas;/ Discute sem cessar, severo, irado, vociferante,/ Certo de estar com a razão, e de estar certo orgulhoso,/ Tais defeitos são comuns, partilhados por todos em parte,/ Mas Wittgenstein pontifica sobre Arte (MONK, 1995, p. 237).
Apesar de sempre quebrar o seu voto de silêncio, como ironizou Bell, Wittgenstein insistiria em uma palestra de janeiro de 1930 que a ética só pode ser "delimitada internamente, por assim dizer":

Minha inclinação, e creio que a de todos os homens que tentaram escrever ou falar sobre ética ou religião, era lançar-me contra os limites da linguagem. Esse lançar-se contra as grades da nossa jaula é algo perfeita e absolutamente sem esperança. A ética, na medida em que brota do desejo de dizer algo sobre o sentido da vida, o bem absoluto, o valor absoluto, não pode ser ciência. $O$ que ela afirma nada acrescenta ao nosso conhecimento. Mas é um documento de uma tendência na mente humana pela qual eu pessoalmente não posso senão ter o mais profundo respeito e que jamais em minha vida poderia ridicularizar (ibid., p. 254).

No entanto, poucos meses antes de proferir essa palestra, Wittgenstein anotou em seu caderno, lançando-se contra os "limites da linguagem": "O que é bom é também divino. Por mais estranho que tal possa parecer, essa afirmação resume a minha ética. Só algo de sobrenatural pode expressar o sobrena- 
tural" (WITTGENSTEIN, 1992a, p. 15). E, por mais estranho que tal possa parecer, "não resta dúvida que, embora considerasse a ética um campo sobre o qual nada se pode dizer, Wittgenstein refletia e tinha muito a dizer sobre problemas morais", reconheceu Monk (1995, p. 254). "Na verdade, poderíamos dizer que sua vida foi dominada por um embate moral: o esforço para ser anständig (decente) - o que para ele significava, acima de tudo, superar as tentações de ser desonesto provocadas pelo orgulho e pela vaidade." E registros dessa tendência de Wittgenstein de refletir e dizer sobre problemas éticos e morais, pela qual eu pessoalmente não posso senão ter o mais profundo respeito e que jamais em minha vida poderia ridicularizar, não faltam. Em carta a Paul Engelmann datada de poucos meses antes da publicação do Tractatus, por exemplo, Wittgenstein confessou ao amigo, lançando-se novamente contra os "limites da linguagem":

$\mathrm{Na}$ realidade, encontro-me num estado mental que é terrível para mim. Já o sofri diversas vezes antes: o estado de não ser capaz de superar determinado fato. É um estado lastimável, eu sei. Só consigo enxergar um remédio e este, é claro, consiste em pôr um fim ao fato. (...) Sei que cometer suicídio é sempre uma coisa imunda a fazer. Certamente não se pode desejar a própria destruição, e qualquer um que tenha visualizado o que envolve a prática do ato de suicídio sabe que ele é sempre uma precipitação das próprias defesas. Nada pior do que ser constrangido a tomar-se de surpresa.

Mas naturalmente tudo acaba se resumindo no fato de que não tenho fé! (ibid., p. 178).

Pouco tempo mais tarde, em 13 de janeiro de 1922 - portanto, menos de um ano depois da publicação do Tractatus -, Wittgenstein iria mais uma vez se lançar contra os "limites da linguagem", tendo anotado em seu caderno:

Senti de repente minha completa nulidade e percebi que Deus poderia exigir de mim o que quisesse sob a condição de que minha vida ficasse imediatamente desprovida de sentido se eu fosse desobediente. Pensei imediatamente se eu não poderia declarar que tudo aquilo seria uma ilusão e não uma ordem de Deus; mas ficou claro para mim que eu, então, teria de declarar que toda a religião em mim seria uma ilusão. Que eu teria de negar o sentido da vida. (...) Senti que estava completamente destroçado e nas mãos de Deus, que a qualquer mo- 
mento poderia fazer comigo o que bem quisesse. Sentia que Deus poderia a qualquer momento me obrigar a confessar minhas baixezas. Que a qualquer momento Ele poderia me obrigar a assumir o mais terrível e que eu não estava preparado para assumir o mais terrível. Que eu não estava preparado para renunciar agora à amizade e a toda felicidade terrena. (...) Como disse, esta noite me dei conta da minha total nulidade. Deus dignouse a mostrá-la para mim. Enquanto isso pensei continuamente em Kierkegaard e acreditei que meu estado era o de "temor e tremor" (WITTGENSTEIN, 2012a, p. 36-38).

Essa anotação refere-se a um sonho que Wittgenstein tinha tido naquela noite e, ao lado de outras tantas anotações anteriores e posteriores, evidencia como ele nunca se calou sobre aquilo de que supostamente não se pode falar - nem deixou de ler autores que se lançaram contra os "limites da linguagem”, como Kierkegaard, que ele não só considerava "o mais profundo pensador" do século 19, mas também "um santo" (DRURY, 1984a, p. 87).

Curiosamente, porém, mesmo no início dos anos 1930, quando já havia se dado conta de que a verdade dos pensamentos comunicados no Tractatus não era realmente "intocável e definitiva", como havia afirmado no prefácio do livro, Wittgenstein manteria a convicção de que nada dizer sobre religião era o mais adequado, como confidenciou a Maurice Drury: "Se for para você e eu vivermos uma vida religiosa, não será por falarmos muito sobre religião, mas sim porque de alguma maneira nossas vidas são diferentes" (DRURY, 1984b, p. 114). Mas Wittgenstein, em seu esforço para ser decente, nunca deixou de falar e de escrever muito sobre religião, sobre Deus, sobre fé, sobre ética: "Um ser que esteja em ligação com Deus é forte" (WITTGENSTEIN, 2010a, p. 54), escreveu, por exemplo, no fim de 1930. Anos depois, em 1937, Wittgenstein anotaria em seu caderno:

O cristianismo não é uma doutrina, quero dizer, não é uma teoria sobre o que aconteceu e virá a acontecer à alma humana, mas uma descrição de algo que na realidade ocorre na vida humana. Pois a "consciência do pecado" é um acontecimento real, e igualmente o desespero e a salvação pela fé (WITTGENSTEIN, 1992a, p. 48).

Anos antes, em 1917, Wittgenstein havia escrito a Engelmann: "E é assim que as coisas são: se não tentamos exprimir o que é inexprimível então nada se perde. Mas o inexprimível es- 
tará - inexprimivelmente - contido naquilo que foi expresso" (MONK, 1995, p. 145). E é assim que as coisas são, como atestam as citações acima: Wittgenstein nunca cessou de se exprimir sobre o que dizia ser inexprimível, nem antes, nem durante, nem depois de ter escrito o Tractatus logico-philosophicus.

\section{O homem com os evangelhos no Cír- culo de Viena}

"Um dos livros menos explícitos jamais publicados - um enigma, ou roman à clef, a que o leitor pode aduzir qualquer uma de uma dúzia de diferentes interpretações" (JANIK \& TOULMIN, 1991, p. 2), o Tractatus suscitou todo tipo de mal-entendido. Nenhum deles, porém, foi tão significativo quanto o dos neopositivistas do Círculo de Viena, que, a despeito de seu logicismo e cientificismo, veneravam Wittgenstein como a uma divindade, como o testemunhou A. J. Ayer (GOLDESTEIN, 2008, p. 91). Rudolf Carnap, por exemplo, confessou, lembrando-se de sua reação ao ver Wittgenstein absorto com os poemas do místico indiano Rabindranath Tagore:

Quando lemos pela primeira vez o livro de Wittgenstein no Círculo, eu havia erroneamente acreditado que sua atitude em relação à metafísica era semelhante à nossa. Eu não prestara atenção suficiente às asser- ções sobre o místico presentes no livro, uma vez que seus sentimentos e ideias nessa área divergiam por demais dos meus. Somente o contato pessoal permitiu que eu compreendesse mais claramente sua posição nesse ponto (MONK, 1995, p. 226).

Somente o contato pessoal permitiu também que os positivistas lógicos compreendessem mais claramente as afinidades que Wittgenstein reconhecia ter com filósofos como Santo Agostinho, Kierkegaard e Heidegger - e estes, é claro, "não são nomes que se esperaria ouvir mencionados nas conversas do Círculo de Viena, exceto como alvos de injúria" (ibid., p. 259). Wittgenstein admirava Santo Agostinho a ponto de considerar suas Confissões "o livro mais sério que já foi escrito" (DRURY, 1984a, p. 90). Ele o leu quando foi feito prisioneiro em Monte Cassino, na Itália, ao fim da Primeira Guerra Mundial (SOMAVILLA, 2010, p. 202). Antes da guerra, Wittgenstein já havia lido e apreciado As variedades da experiência religiosa, de William James (MONK, 1995, p. 112). Durante o conflito, em meio a seu "despertar religioso" (ibid., p. 143), Wittgenstein leria O Anticristo, de Nietzsche (ibid., p. 120), e O evangetho explicado, de Tolstoi (ibid., p. 115). Segundo Monk (ibid.), o livro de Tolstoi se tornou para Wittgenstein "uma espécie de talismã" na guerra. Wittgens- 
tein "carregava-o onde quer que fosse e leu-o tantas vezes que decorou trechos inteiros. Passou a ser conhecido de seus companheiros como 'o homem com os evangelhos'”. Desnecessário dizer que "o homem com os evangelhos" não seguia o "método correto da filosofia"...

Anos depois da guerra, em 1930, Wittgenstein diria com todas as letras a Drury: "Não pense que eu desprezo a metafísica" (DRURY, 1984b, p. 105). Essa asserção certamente surpreenderia os positivistas lógicos do Círculo de Viena. No entanto, em dezembro do mesmo ano, Friedrich Waismann perguntou a Wittgenstein se a existência do mundo tem relação com o ético, ao que Wittgenstein teria respondido, novamente lançando-se contra os "limites da linguagem": "Que existe aqui uma conexão, os homens sentiram e expressaram desta maneira: Deus-Pai criou o mundo, Deus-Filho (ou a palavra, o que sai de Deus) é o ético. Que se divida a divindade para logo voltar-se a unila significa que existe aqui uma conexão" (WAISMANN, 1973, p. 104). Dizendo algo de metafísico, Wittgenstein já havia concluído no próprio Tractatus: "Como seja o mundo, é completamente indiferente para o Altíssimo. Deus não se revela no mundo" (6.432). Mas os positivistas lógicos não prestaram atenção suficiente a essa asserção de Wittgenstein, que reveladoramente disse a seu companheiro de prisão na Itália Franz Parak que preferiria ser padre no pósguerra, mas que como professor poderia ler o evangelho com as crianças (MCGUINNESS, 1991, p. 358). Outro fato revelador, depois de abandonar o magistério em 1926, Wittgenstein cogitou se tornar monge (VON WRIGHT, 1990, p. 21). Assim, ele definitivamente não era o positivista que Carnap e os colegas esperavam.

A disparidade entre quem os positivistas lógicos imaginavam que Wittgenstein era e quem ele efetivamente era, no entanto, não impediu que sua influência no Círculo de Viena fosse profunda. E, dadas as contradições e contrassensos do autor do Tractatus logico-philosophicus, ${ }^{2}$ não admira que o princípio fundamental do positivismo lógico, o verificacionismo, seja um contrassenso. De acordo com esse princípio, formulado por Wittgenstein nos anos 1920, o sentido de uma proposição é seu meio de verificação - ou melhor, como o próprio Wittgenstein disse a seus alunos no início dos anos 1930: "O sentido de uma proposição é o modo de sua verificação" (WITTGENSTEIN, 1980, p. 66). Como consequência do verificacionismo, nessa fase Wittgenstein manteria toda a temática ética e estética na região mística, inexprimível, afirmando que "julgamentos éticos e estéticos não são proposições porque não

\footnotetext{
${ }^{2}$ Para a análise de outros aspectos contraditórios na filosofia wittgensteiniana, ver Silva (2018a, 2018b, 2018c, 2019a, 2019b e 2020).
} 
podem ser verificados" (ibid.). Contudo, como apontado já nas décadas de 1920 e 1930 (JANIK \& TOULMIN, 1991, p. 242), o próprio princípio, que Wittgenstein não tardaria a abandonar (MONK, 1995, p. 263), tampouco pode ser verificado. Seu enunciado, portanto, seria uma "pseudoproposição"? Uma "elucidação"?

\section{Entre a teoria e a prática}

Se a pedra angular da primeira filosofia de Wittgenstein é a teoria pictórica do significado - derivada da analogia entre a proposição e o modelo de acidente de carro no tribunal de Paris -, a pedra angular da segunda filosofia de Wittgenstein é a ideia de que a significação de uma palavra é seu uso na linguagem - derivada da analogia entre a linguagem e um jogo. Essa analogia, de acordo com Norman Malcolm (1990, p. 69), teria surgido a Wittgenstein enquanto ele passeava com Freeman Dyson por um campo onde viu pessoas jogando futebol. Trata-se, no entanto, de uma velha analogia que já havia sido feita por outros autores. Entre eles, o filósofo austro-húngaro Fritz Mauthner, cujo monumental Beiträge $z$ u einer Kritik der Sprache Wittgenstein conhecia desde a juventude (JANIK \& TOULMIN, 1991, p. 140). Conforme
Janik e Toulmin (ibid.), para Mauthner a linguagem é "parte integrante de um complexo social específico", "um fenômeno social, a ser apreendido juntamente com outros costumes associados dos indivíduos que a usam". Assim,

(os textos da segunda filosofia de Wittgenstein) reviveram muitas posições e teses já expostas por Mauthner em 1901 por exemplo, a ideia de que as regras da linguagem são como as regras de um jogo, e de que a própria palavra "linguagem" é um termo abstrato geral, que precisamos desembrulhar para ver como, na prática real, os homens empregam as expressões de suas linguagens, nos contextos de todas as suas variadas culturas (ibid., p. 273).

$\mathrm{Na}$ verdade, considerando-se a obra de Mauthner, fica claro que "a ideia de que Wittgenstein, nas Investigações filosóficas, 'propôs uma filosofia da linguagem inteiramente nova' (Hacker, 1995, p. 9) $)^{3}$ é absurda" (GELLNER, 1998, p. 156), já que "essa alegada nova filosofia era um lugar-comum" (ibid.) entre os intelectuais do Império AustroHúngaro, no qual Wittgenstein nasceu e cresceu..$^{4}$ Mas mais importante: di-

\footnotetext{
${ }^{3}$ HACKER, Peter. "Thought, language and reality."

${ }^{4}$ Para uma discussão detalhada sobre como Wittgenstein retomou nas Investigações filosóficas "muitas posições e teses já expostas" por outros autores, ver Silva (2017).
} 
ferentemente de Mauthner, Wittgenstein levou a analogia entre a linguagem e um jogo às últimas consequências, $\mathrm{o}$ que mais uma vez resultou em contradições grosseiras. No $\S 199$ das Investigações filosóficas, por exemplo, Wittgenstein afirma: "Seguir uma regra, fazer uma comunicação, dar uma ordem, jogar uma partida de xadrez são hábitos (costumes, instituições). Compreender uma frase significa compreender uma linguagem. Compreender uma linguagem significa dominar uma técnica". Nas Observações sobre os fundamentos da matemática (VI, § 43), Wittgenstein retoma a analogia entre a linguagem e um jogo e completa: "As palavras 'linguagem', 'proposição', 'ordem', 'regra', 'operação de cálculo', 'experimento', 'seguir uma regra' remetem a uma técnica, a um costume". Realmente, essas palavras remetem a uma técnica, a um costume, e as regras do jogo de xadrez, como as regras de qualquer jogo, são seguidas "cegamente" (WITTGENSTEIN, 1999, § 219), porque "se você segue outras regras que não as do xadrez você está jogando outro jogo" (WITTGENSTEIN, 2003, p. 139). As regras linguísticas, no entanto, não são seguidas cegamente. Por ter desconsiderado essa diferença, Wittgenstein não apenas afirma nas Investigações filosóficas (II, XI) que "o gênero de certeza é o gênero do jogo de linguagem" como decreta: "A filosofia não deve, de modo algum, tocar no uso efetivo da linguagem; em último caso, pode apenas descrevê-lo.
(...) A filosofia deixa tudo como está" (ibid., § 124). Pelo contrário: a filosofia deve tocar no uso efetivo da linguagem; não apenas descrevê-lo. A filosofia não deixa tudo como está. Prova disso é que "a linguagem comum é um cemitério de restos da especulação filosófica do passado" (RUSSELL, 2013, p. 101). Além do mais, Wittgenstein mesmo "não hesitou em introduzir sua própria terminologia técnica ou semitécnica em filosofia (e.g. 'jogos de linguagem', 'conceito de semelhança de família', 'proposição gramatical')" (HACKER, 1996, p. 234). Ou seja, Wittgenstein mesmo não hesitou em tocar no uso efetivo da linguagem. E, para complicar a situação, "Wittgenstein (...) parece ir contra a sua própria ideia de que a filosofia deixa tudo como está por ele mesmo propor uma concepção que não deixa tudo como está" (SNOWDON, 2014, p. 405). Em vista dessas dificuldades, não espanta que alguns wittgensteinianos, como Anthony Kenny (2006, p. xix), achem incompatíveis a explicação da filosofia que Wittgenstein faz e sua atividade filosófica apresentada nas Investigações filosóficas. "Nós somos forçados no fim a fazer uma escolha entre aceitar sua teoria e seguir sua prática", observa Kenny (ibid.). 


\section{Um método por exemplos, pura- mente descritivo?}

Além de afirmar no $§ 124$ das Investigações filosóficas que a filosofia não deve, de modo algum, tocar no uso efetivo da linguagem, podendo, em último caso, apenas descrevê-lo, Wittgenstein sentencia no $§ 109$ : “Toda elucidação deve desaparecer e ser substituída apenas por descrição". 5. As próprias Investigações filosóficas, porém, como ilustram os exemplos abaixo, estão repletas de elucidações, o que reitera que não é possível conciliar a explicação da filosofia feita por Wittgenstein com a totalidade de sua atividade filosófica no livro:

Chamarei também de "jogos de linguagem" o conjunto da linguagem e das atividades com as quais está interligada $(\S 7)$.

O termo "jogo de linguagem" deve aqui salientar que o falar da linguagem é uma parte de uma atividade ou de uma forma de vida $(\S 23)$.

Não considere como evidente, mas como algo notável, o fato de que quadros e histórias de ficção nos proporcionem prazer e ocupem nosso espírito. ('Não considere como evidente' - sig- nifica: admire-se com isso tal como com outra coisa que o inquieta $(. .).(\S 524)$.

Se o sentimento dá à palavra sua significação, então 'significação' significa aqui: aquilo de que se trata ( $\$ 545)$.

Pior: Wittgenstein habitualmente filosofava sobre as cores mesmo tendo afirmado que elas não podem ser descritas:

Quando nos perguntam "Qual a distinção entre azul e vermelho?", sentimos vontade de dizer: um é azul e o outro é vermelho. Mas, naturalmente, isso não significa nada e, na realidade, aquilo em que estamos pensando é na distinção entre as superfícies ou lugares que têm essas cores. Pois, de outra maneira, a questão não faz nenhum sentido.

\section{(..)}

Então, o que estou dizendo significa: o vermelho não pode ser descrito. (...)

\section{(...) não é por acaso que, para}

\footnotetext{
${ }^{5} \mathrm{Na}$ tradução de Marcos G. Montagnolli para a edição da Vozes: "Toda explicação tem que sair e em seu lugar entrar apenas descrição".
} 
definir o significado da palavra "vermelho", a coisa natural seja apontar para um objeto vermelho (WITTGENSTEIN, 2003, p. 159-160).

Ou seja, para Wittgenstein, "à pergunta: 'O que significa 'vermelho', 'azul', 'preto', 'branco'?', poderíamos logo apontar para coisas assim coloridas, - mas isto também é tudo: nossa capacidade de esclarecer os significados não vai adiante" (WITTGENSTEIN, 2009a, III, § 102). Dessa forma, para Wittgenstein, as cores não podem ser descritas e são explicadas ostensivamente. Portanto, seu "método por exemplos" [6 (WITTGENSTEIN, 1999, $\S 133$ ), "puramente descritivo" (WITTGENSTEIN, 1992c, I, § 73), deveria excluir anotações sobre as cores.

\section{Emprego metafísico das palavras}

Muito antes de declarar, no início dos anos 1930, que "a filosofia é na verdade 'puramente descritiva'” (WITTGENSTEIN, 2008, p. 47) e de salientar, no início dos anos 1950, que "nalgum ponto temos de passar da explicação para a mera descrição" (WITTGENSTEIN, 1998, § 189), Wittgenstein já defendia uma concepção descritivista da filosofia. Nas Notas sobre lógica (1913), por exemplo, Wittgenstein afirma que "na filosofia, não há deduções; ela é puramente descritiva" (WITTGENSTEIN, 2004b, p. 155). Com base nessa explicação da filosofia - e nitidamente ignorando as implicações do fato de que, ao contrário das descrições de como usamos peças de xadrez, "as descrições de 'como usamos as palavras' não são neutras” (GELLNER, 1968, p. 71) -, Wittgenstein ponderou: "Só estou descrevendo a linguagem, não explicando qualquer coisa" (WITTGENSTEIN, 2003, p. 47). Mas Wittgenstein, que chegou a afirmar que "uma palavra nova é como uma semente viçosa lançada à terra no campo da discussão" (WITTGENSTEIN, 1992a, p. 14), só estava de fato descrevendo a linguagem, não explicando qualquer coisa? Em outros termos: Wittgenstein, que chegou a ressaltar que "nada é mais importante para nos ensinar a compreender os conceitos de que dispomos do que a construção de conceitos fictícios" (ibid., p. 110), realmente deixou tudo como estava? "Nós reconduzimos as palavras do seu emprego metafísico para seu emprego cotidiano", afirmou Wittgenstein no $\S$ 116 das Investigações filosóficas, aparentemente sem se dar conta de que "a linguagem corrente está cheia de matizes esmaecidos de teorias filosóficas do passado" (RUSSELL, 2013, p. 484485). Em todo caso, o emprego das pa-

\footnotetext{
6Para uma análise dos motivos pelos quais o método por exemplos não "acalma a filosofia" (WITTGENSTEIN, 1999, § 133), ver Silva (2018 e 2020).
} 
lavras feito por Wittgenstein é seu emprego cotidiano? O emprego das palavras e expressões listadas no Dicionário Wittgenstein de Hans-Johann Glock, por exemplo, é seu emprego cotidiano?

\section{Sobre aquilo de que se deve falar}

Apesar de ter escrito ainda em 1930 - portanto, logo no início da elaboração de sua segunda filosofia - que tudo aquilo que se pode alcançar com uma escada não lhe interessava (WITTGENSTEIN, 1992a, p. 21), é notório que Wittgenstein, por assim dizer, sobe por uma escada para propor seu método por exemplos, puramente descritivo. Um método que, como o "método correto da filosofia", não lhe permitiria sequer expressá-lo por proposições. Um método que, como o "método correto da filosofia", foi concebido por Wittgenstein com o intuito de alçá-lo ao posto de "terminus ad quem da grande filosofia ocidental" (WITTGENSTEIN, 2010 a, p. 58), mas que não pode ser sequer defendido empregando-se o próprio método.

\section{Agradecimentos}

Gostaria de agradecer a dois pareceristas anônimos pelas críticas, comentários e sugestões a uma versão anterior deste texto, que muito contribuíram para seu aperfeiçoamento. A responsabilidade pelas posições aqui assumidas, claro, é inteiramente minha.

\section{Referências}

ANSCOMBE, G. E. M. An introduction to Wittgenstein's Tractatus. Bristol: Thoemmes Press, 1996.

BASSOLS, Alejandro Tomasini. Wittgenstein: universalismo, lógica, gramática y lenguaje. Aurora, v. 29, n. 47, p. 611-638, maio/ago. 2017.

BOUWSMA, O. K. Conversas com Wittgenstein. Lisboa: Relógio D’Água Editores, 2005.

DRURY, M. O'C. Some notes on conversations with Wittgenstein. In: RHEES, Rush (Ed.). Recollections of Wittgenstein: Hermine Wittgenstein; Fania Pascal; F. R. Leavis; John King; M. O'c. Drury. Oxford: Oxford University Press, 1984a, p. 76-96.

. Conversations with Wittgenstein. In: RHEES, Rush (Ed.). Recollections of Wittgenstein: Hermine Wittgenstein; Fania Pascal; F. R. Leavis; John King; M. O'c. Drury. Oxford: Oxford University Press, 1984b, p. 97-171.

FOGELIN, Robert J. Wittgenstein. 2. ed. Londres; Nova York: Routledge, 1995.

GELLNER, Ernest. Language and solitude: Wittgenstein, Malinowski and the Habsburg dilemma. Cambridge: Cambridge University Press, 1998.

. Words and things. Harmondsworth: Pelican Books, 1968.

GOLDSTEIN, Rebecca. Incompletude: a prova e o paradoxo de Kurt Gödel. São Paulo: Companhia das Letras, 2008.

GLOCK, Hans-Johann. Dicionário Wittgenstein. Rio de Janeiro: Jorge Zahar, 1998.

HACKER, P. M. S. Insight and illusion. 2.ed. Oxford: Oxford University Press, 1986. 
Wittgenstein's place in twentieth-century analytic philosophy. Oxford: Blackwell Publishers, 1996.

JANIK, Allan; TOULMIN, Stephen. A Viena de Wittgenstein. Rio de Janeiro: Editora Campus, 1991.

KENNY, Anthony. Wittgenstein. Oxford: Blackwell Publishing, 2006.

KING, John. Recollections of Wittgenstein. In: RHEES, Rush (Ed.). Recollections of Wittgenstein: Hermine Wittgenstein; Fania Pascal; F. R. Leavis; John King; M. O'c. Drury. Oxford: Oxford University Press, 1984, p. 68-75.

KUUSELA, Oskari; MCGINN, Marie (Ed.). The Oxford Handbook of Wittgenstein. Oxford: Oxford University Press, 2014.

MALCOLM, Norman. Ludwig Wittgenstein: esbozo biografico de G. H. von Wright. Madri: Biblioteca Mondadori, 1990.

MCGUINNESS, Brian. Wittgenstein: el joven Ludwig (1889-1921). Madri: Alianza Editorial, 1991.

MONK, Ray. Wittgenstein: o dever do gênio. São Paulo: Companhia das Letras, 1995.

QUINE, W. V. Palavra e objeto. Petrópolis: Vozes, 2010.

RHEES, Rush (Ed.). Recollections of Wittgenstein: Hermine Wittgenstein; Fania Pascal; F. R. Leavis; John King; M. O'c. Drury. Oxford: Oxford University Press, 1984.

RUSSELL, Bertrand. História do pensamento ocidental: a aventura dos pré-socráticos a Wittgenstein. Rio de Janeiro: Nova Fronteira, 2013. . Introdução ao Tractatus logico-philosophicus. In: WITTGENSTEIN, Ludwig. Tractatus logico-philosophicus. São Paulo: Edusp, 2010, p. 113-128.

SILVA, G. A. F. A filosofia de Ludwig Wittgenstein à luz do diagnóstico de autismo. Griot: Revista de Filosofia, v. 19, n. 1, p. 226-253, 2019a.

. Considerações sobre o método por exemplos de Ludwig Wittgenstein. Griot: Revista de Filosofia, v. 20, n. 2, p. 140-153, 2020.

Observações sobre a filosofia da matemática de Ludwig Wittgenstein. Griot: Revista de Filosofia, v. 17, n. 1, p. 97-113, 2018a.

Observações sobre a filosofia da mente de Ludwig Wittgenstein. Problemata, v. 9, n. 4, p. 218-233, 2018b.

Observações sobre a meta final do modo de fazer filosofia de Ludwig Wittgenstein. Principia, v. 22, n. 3, p. 411-438, 2018c.

Os precursores esquecidos de Ludwig Wittgenstein. Griot: Revista de Filosofia, v. 21, n. 2, p. 89-114, 2021.

Wittgenstein além dos limites da linguagem. Reflexões, v. 14, n. 1, p. 130-146, 2019 b.

SLUGA, Hans D. Wittgenstein. Malden, MA: Wiley-Blackwell, 2011.

SNOWDON, Paul. Private experience and sense data. In: KUUSELA, Oskari; MCGINN, Marie (Ed.). The Oxford Handbook of Wittgenstein. Oxford: Oxford University Press, 2014, p. 402-428.

SOMAVILLA, I. Notas e comentários. In: WITTGENSTEIN, Ludwig. Movimentos de pensamento: diários de 193032/1936-37. São Paulo: Martins Fontes, 2010, p. 165-252.

STRAWSON, Peter F. Análise e metafísica: uma introdução à filosofia. Tradução de Armando Mora de Oliveira. São Paulo: Discurso Editorial, 2002.

VON WRIGHT, G. H. Esbozo biográfico. In: MALCOLM, Norman. Ludwig Wittgenstein: esbozo biográfico de G. H. von Wright. Madri: Biblioteca Mondadori, 1990, p. 11-31.

WAISMANN, Friedrich. Ludwig Wittgenstein y el Círculo de Viena. Cidade do México: Fondo de Cultura Económica, 1973.

WITTGENSTEIN, Ludwig. Anotações sobre as cores. Campinas: Editora da Unicamp, 2009.

Cadernos: 1914-1916. Lisboa: Edições 70, 2004a.

Cultura e valor. Lisboa: Edições 70, 1992a.

Da certeza. Lisboa: Edições 70, 1998.

Experiência (onírica) noturna - Anotação de diário de 13/1/1922. In: WITTGENSTEIN, Ludwig. Luz e sombras: uma experiência (onírica) noturna e um fragmento de carta. São Paulo: Martins Fontes, 2012a, p. 34-38.

Fichas (Zettel). Lisboa: Edições 70, 1992b.

Gramática filosófica. São Paulo: Loyola, 2003.

Investigações filosóficas. São Paulo: Abril Cultural, 1999. (Coleção: Os pensadores).

Investigações filosóficas. Petrópolis; Bragança Paulista: Editora Vozes, 2013.

Luz e sombras: uma experiência (onírica) noturna e um fragmento de carta. São Paulo: Martins Fontes, $2012 \mathrm{~b}$.

Movimentos de pensamento: diários de 1930-32/1936-37. São Paulo: Martins Fontes, 2010a.

Notas sobre lógica. In: WITTGENSTEIN, Ludwig. Cadernos: 1914-1916. Lisboa: Edições 70, 2004b, p. 137-157.

Observaciones sobre los fundamentos de la matemática. Madri: Alianza Editorial, 1987.

O livro azul. Lisboa: Edições 70, 2008.

O livro castanho. Lisboa: Edições 70, 1992c.

Tractatus logico-philosophicus. São Paulo: Edusp, $2010 \mathrm{~b}$.

Wittgenstein's lectures. Cambridge, 1930-1932: from the notes of John King and Desmond Lee. Lee, Desmond

(Ed.). Totowa: Rowman and Littlefield, 1980. 
Recebido: 02/02/2021

Aprovado: 12/03/2021

Publicado: $30 / 04 / 2021$ 
